\title{
Review \\ The Challenge of Subjective Cognitive Complaints and Executive Functions in Middle-Aged Adults as a Preclinical Stage of Dementia: A Systematic Review
}

\author{
Felipe Webster-Cordero ${ }^{1,2, *}$ and Lydia Giménez-Llort 1,3,*(D) \\ 1 Department of Psychiatry and Forensic Medicine, School of Medicine, Universitat Autònoma de Barcelona, \\ E-08193 Barcelona, Spain \\ 2 Hospital Santa Inés, Cuenca 010107, Ecuador \\ 3 Institut de Neurociències, Universitat Autònoma de Barcelona, E-08193 Barcelona, Spain \\ * Correspondence: felipe.webster@autonoma.cat (F.W.-C.); lidia.gimenez@uab.cat (L.G.-L.); \\ Tel.: +593-98-488-4724 (F.W.-C.); +34-93-5812378 (L.G.-L.)
}

Citation: Webster-Cordero, F.; Giménez-Llort, L. The Challenge of Subjective Cognitive Complaints and Executive Functions in Middle-Aged Adults as a Preclinical Stage of Dementia: A Systematic Review. Geriatrics 2022, 7, 30. https://doi.org/ 10.3390 /geriatrics7020030

Academic Editor: Phyo Kyaw Myint

Received: 7 February 2022

Accepted: 4 March 2022

Published: 8 March 2022

Publisher's Note: MDPI stays neutral with regard to jurisdictional claims in published maps and institutional affiliations.

Copyright: (C) 2022 by the authors. Licensee MDPI, Basel, Switzerland. This article is an open access article distributed under the terms and conditions of the Creative Commons Attribution (CC BY) license (https:// creativecommons.org/licenses/by/ $4.0 /)$.

\begin{abstract}
Subjective cognitive complaints correspond to a heterogeneous construct that frequently occurs in the early stages of older adult life. Despite being a common source of worry for middle-aged people, it can be underestimated when clinical and neuropsychological assessments discard any underlying pathological processes. Negative age stereotyping but also self-stereotyping can contribute to doing so. Although its diagnosis is a challenge, its implication as a possible predictor of mild cognitive impairment or dementia increases the interest in its early diagnosis and intervention. The present systematic review analyzes the empirical data on the relationship between these complaints and early executive dysfunction with possible predictive value for preclinical stages of dementia. The sixteen papers obtained from the PubMed and Embase databases were exploratory, cross-sectional and prospective in scope. The studies corroborated the relationship between subjective cognitive complaints and some executive processes, which is noteworthy since many people with subjective executive complaints progress to dementia. The relational studies confirmed that impaired executive performance is associated with CSF biomarkers and reduced cortical volume in specific brain regions. However, the heterogeneity of reports in these studies demands stronger efforts in future research with specific tools applied in clinical and neuropsychological assessments and analyzed under a gender perspective.
\end{abstract}

Keywords: subjective cognitive complaints; stereotypes; aging; complaints; executive functions; memory; mild cognitive impairment; dementia

\section{Introduction}

With the aging population, geriatricians highlight the relevance of disease prevention and diagnosis of old-age-specific diseases and the best use of healthcare professionals specialties [1]. However, in this context, age stereotypes are known to influence behavioral, physical and cognitive outcomes among healthy older adults [2-4]. Moreover, the health care professionals' beliefs and attitudes toward older people may also exert a significant impact [5]. Thus, stigmatization of older people has been shown to induce the overestimation of their age-related cognitive decline and the common perception that older people have worse cognitive competencies [2]. Growing evidence shows that these negative aging stereotypes impair the performance of healthy older adults on cognitive tests, while positive age stereotyping exerts less intense effects [2]. Thus, the impact of the age-based stereotype threat (the threat of being judged stereotypically) on older adults' episodic and working memory, false memory susceptibility and subjective age has been recently reported [6-10].

Research on the role of age stereotypes and subjective aging in health across the life span identifies several theoretical approaches for potential mechanisms to explain how 
personal views of aging might influence health-related outcomes in later life [11]. In fact, self-stereotyping also has long-term negative effects. According to the internalization hypothesis, holding more negative age stereotypes and perceiving more age discrimination are associated with feeling older, lower self-esteem and worse perceptions of one's own aging [7]. Similarly, internalized negative age stereotypes and subjective cognitive impairment have been related to increased depressive effects despite not being related to age-related dysregulations of cortisol [12]. In contrast, essentialist beliefs about aging seem to moderate the impact of negative age stereotypes on older adults' performance and physiological reactivity [13].

Despite most research on age stereotypes being focused on the above-mentioned external/internal distortions referred to the older adult, nihilist aptitudes towards the inherent limitations of advanced aging and underestimations during middle adulthood can also occur [5]. Gerontologists warn that negative aging stereotypes can decrease performance on short cognitive tests widely used in primary care to screen for predementia [14]. However, on the other hand, the cognitive decline that occurs after the age of 50 or 60 is accompanied by minimal changes in some cognitive processes that are, in many cases, self-perceived by the individual but yet undetectable by classical neuropsychological assessments primarily focused on declarative memory. Hence, the term subjective cognitive impairment (SCI) associated with a subjective decline in one or more cognitive areas (attention, memory, reasoning, language, etc.) is not objectively measurable after a neurocognitive assessment despite being reported by the subject or a close person [15]. Its possible relationship with dementia points to this challenging SCI diagnosis and understanding as a subject of growing research interest, since it could have a crucial role in applying early and personalized preventive and therapeutic interventions [16,17].

An increasing number of young adults calls at clinical centers for clinical consultation due to problems in their cognitive performance, reporting problems with memory, concentration, or reasoning. In the case of middle-aged adults, this awareness usually becomes a source of worry about a predictive value for a worse clinical condition, a prelude to dementia. People's subjective perception of their cognitive performance is highly variable and the heterogeneity of these subjective cognitive complaints makes differential diagnosis a challenge $[18,19]$.

In fact, cognitive symptomatology in adults may be directly related to depressive symptoms or personality characteristics that influence their perception of their cognitive performance [20,21]. Moreover, the sum of these factors may be a predictor of a negative perception of quality of life [22]. Therefore, in many cases, neuropsychological assessment discards the existence of an actual cognitive impairment underlying the subjective complaints [23]. In the current pandemic scenario, the number of middle-aged adults with cognitive complaints has increased dramatically, becoming a topic of growing interest $[24,25]$. This subclinical condition has been usually exclusively associated with loss of memory processes, perhaps due to the lack of specificity when assessing neurocognitive processes. In this sense, questionnaires or standardized tests to assess subjective memory complaints are not analyzed in detail; many of them do not assess all the cognitive processes involved or do not assess qualitative aspects, via which clinically significant data are obtained [26,27].

Due to the significant heterogeneity of the neurocognitive processes involved in subjective cognitive impairment, the neuropsychological assessment is an essential diagnostic tool together with the multi- and interdisciplinary clinical study [28]. There are conflicting data on how this symptomatology manifests and whether it can be determined as a syndrome distinct from mild cognitive impairment (MCI) and dementia [29]. However, although there is not a unified criterion for this entity yet, biomarkers and evidence of anato-functional changes through neuroimaging studies are now known [30,31]. Regarding the dysfunctional neuroanatomical substrate, frontal executive processes seem to be, in part, the target of several lines of research where they are analyzed as possible initial symptoms of this not yet determined complex clinical picture. Therefore, the present review 
aims to systematically analyze the emerging empirical data on the relationship between subjective cognitive complaints (SCCs) and executive functions in middle-aged adults to help understand possible deficits at this level in the preclinical stages of dementia. This would also provide evidence to counteract the underestimation of SCCs before clinical diagnosis using the biomedical model.

\section{Materials and Methods}

In the present study, a systematic review on the relationship between subjective cognitive complaints and executive functions was carried out, following the guidelines of the PRISMA [32] method for its correct elaboration (see Figure 1).

\section{SUBJECTIVE COGNITIVE COMPLAINTS and EXECUTIVE FUNCTION}

PRISMA Flow chart at four levels

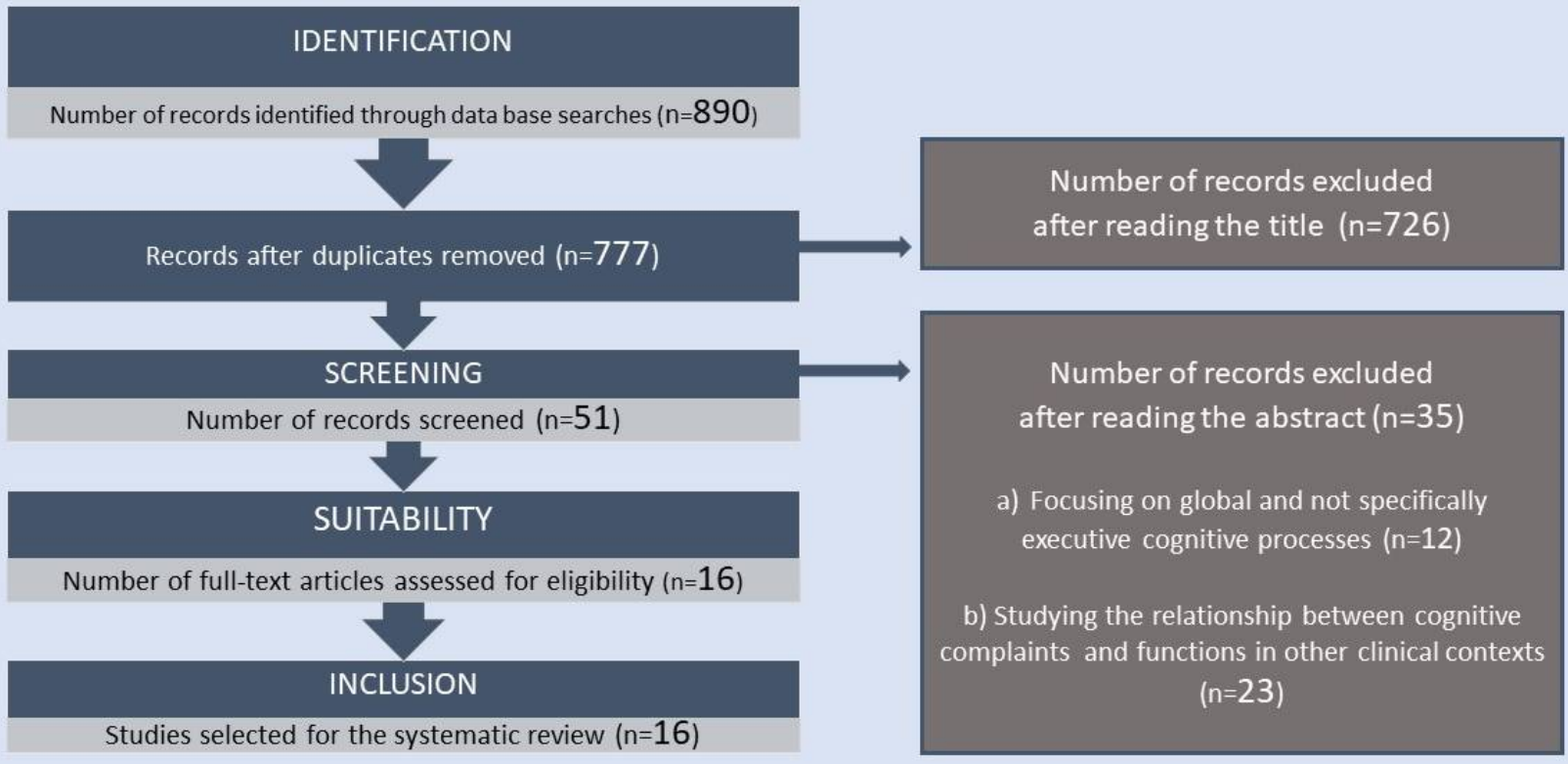

Figure 1. Flow chart of the systematic review on subjective cognitive complaints and executive functions.

\subsection{Systematic Search (Databases, Descriptors, Search Formulas)}

Through the systematic search, scientific publications from 2005 (when the literature on "subjective complaints" started to grow) to the present on the chosen topic were analyzed, using the PubMed and Embase databases as the primary tool. The terms "subjective", "memory", "cognitive", "complaints", "executive functions" and "working memory" used in the search with the Booleans "AND" and "OR" yielded 890 results as possible sources of analysis, after which inclusion and exclusion criteria were established.

\subsection{Inclusion Criteria}

1. Empirical research on the relationship between subjective cognitive complaints and executive functions in preclinical stages of dementia;

2. Papers published from 2005 to the present and with a study population specificity of 60 years of age and older. 


\subsection{Exclusion Criteria}

3. Papers addressing the topic of subjective cognitive complaints in a general or specific way in other clinical contexts;

4. Studies analyzing executive functions in stages where there is already a diagnosis of dementia in advanced stages.

\subsection{Flow Chart}

Following these criteria, on reading the title of the initially selected articles, 51 papers were chosen. After reading the abstract, 35 were discarded; some focused on global cognitive processes and not specifically executive ones $(n=12)$ and others studied the relationship between subjective cognitive complaints and executive functions in other clinical contexts $(n=23)$. Finally, 16 articles were selected for review, as they focused on studying the relationship between some executive processes with SCCs and their involvement in the subclinical stages of mild cognitive impairment and dementia.

\section{Results}

Table 1 summarizes the empirical studies and depicts the main findings on the relationship between subjective cognitive complaints and executive functions.

The number of studies on the relationship between subjective cognitive complaints and executive functions was scarce, but the overall data are based on atal sample of 5137 participants gathered from western (USA, Australia, and Central and Southern Europe) and oriental (Korea) countries. The sociodemographic variables included sex (with a 1:3 Women:Men ratio) and years of education, but none analyzed the data on subjective complaints in a segregated manner. All the studies confirmed the hypothesis of a direct link between these two psychological constructs, providing evidence at the neuropsychological but also neuroimaging and biomarker levels. 
Table 1. Summary of the studies analyzing the relationship between subjective cognitive complaints and executive functions.

Authors

Rapp and Reischies (2005) [33]

Grober et al. (2008) [35]

Saunders and Summers (2010) [36]

Sample

Results

\section{7 participants $(83 \mathrm{~W}$ and $84 \mathrm{M})$ :}

5 cases who developed $\mathrm{A}$

$$
\text { (7 W and } 8 \mathrm{M})
$$

Mean age: 86.17 years

Mean years of education: 11.43

172 cases who did not develop AD (76 W and $76 \mathrm{M})$

Mean age: 79.08 years

Mean years of education: 11.30

Country: Germany

87 participants ( $54 \mathrm{~W}$ and $33 \mathrm{M}$ ):

$30 \mathrm{HC}$ subjects (21 W and $9 \mathrm{M})$

$$
\text { Mean age: } 72 \text { years }
$$

Mean years of education: 17

28 SCC subjects (20 W and $8 \mathrm{M}$ )

Mean age: 74 years

Mean years of education: 16

29 MCI subjects ( $13 \mathrm{~W}$ and $16 \mathrm{M}$ ) Mean age: 74

Mean years of education: 16

Country: United States
92 subjects with incident $A D$ assessed for 15 years prior to diagnosis $(48 \mathrm{~W}$ and $44 \mathrm{M})$

Mean years of education: 16.5

Country: United States, Netherlands
Mean age: 79.8 years
NEUROPSYCHOLOGY

MMSE, TMT part B, Digit Symbol Substitution Test, Digit Letter test,

Identical Pictures

\section{Longitudinal study (4 years)}

In total, 15 participants developed Alzheimer's disease at 4 years (scoring low

on all follow-up assessments).
131 subjects $(68 \mathrm{~W}$ and $63 \mathrm{M})$

25 HC subjects

Mean age: 69 years

Mean years of education: 13.5

32 subjective $\mathrm{MCI}$

Mean age: 71 years

Mean years of education: 13

60 amnestic MCI

Mean age: 71 years

Mean years of education: 13.1

14 mild AD

MMSE, CVLT-II, DRS-2, WCST, D-KEFS,

WMS-III, BRIEF-A

The participants with MCI and SCCs reported significant difficulties with selective aspects of executive functioning (working memory) In addition, it was more likely that their informants reported the same difficulties.

Mean age: 76 years

Mean years of education: 12

Country: Australia

\section{NEUROPSYCHOLOGY}

Wechsler Test of Adult Reading (WTAR);

estimated full-scale intelligence quotient (FSIQ); Naming Test (BNT);

Rey Auditory Verbal Learning Test (RAVLT);

Paired AssociateLearning (PAL)
The decline in the cognitive performance in episodic memory tests accelerated 7 years prior to diagnosis; this was 2-3 years for executive-function performance (associated with pathological signs in the frontal circuits) while verbal-intelligence performance declined in the vicinity of diagnosis. 
Table 1. Cont.

Authors
Sample

132 participants with SCCs (56 W and $76 \mathrm{M}$ ) Mean age: 61.4 years

Mean years of education: 6

Country: Netherlands

52 subjects ( $253 \mathrm{~W}$ and $269 \mathrm{M})$ :

$07 \mathrm{CN}$ subjects $(138 \mathrm{~W}$ and $169 \mathrm{M})$ Mean age: 73.9 years

71 subjects with SCCs $(25 \mathrm{~W}$ and $46 \mathrm{M})$ Mean age: 71.6 years

Toledo et al. (2015) [38] 51 subjects with executive SCI (21
Mean age: 77.3 years

66 subjects with memory SCI ( $49 \mathrm{~W}$ and $17 \mathrm{M})$

Mean age: 75 years

27 subjects with multi-domain SCI ( $20 \mathrm{~W}$ and $7 \mathrm{M})$

Mean age: 78 years

Country: United States

Methodology

NEUROPSYCHOLOGY

Neuropsychological assessments with 1-2 years

follow-up (MMSE)

CSF biomarker data on $\beta$-amyloid,

total tau, hyperphosphorylated tau-181

\section{Results}

Patients meeting preclinical AD criteria showed deterioration of memory, executive functions and global cognition over time,

associated with evidence of CSF.

MMSE total scores, delayed recall and initiation/perseveration subscales were significantly lower than the control group.

265 participants $(178 \mathrm{~W}$ and $79 \mathrm{M})$

$188 \mathrm{CN}$ subjects $(120 \mathrm{~W}$ and $60 \mathrm{M})$

Mean age: 71.94 years

Mean years of education: 9.69

77 subjects with pre-DC

(58 $\mathrm{W}$ and $19 \mathrm{M}$ )

Mean age: 72.64 years

Mean years of education: 9.64

Country: Korea
CSF BIOMARKERS

Analysis of CSF biomarker data

NEUROIMAGING

Hippocampal volume measurements and

$$
\text { MRI-SPARE-AD value }
$$

Hypometabolic convergence index

Posterior cingulate metabolic rate for glucose
Conversion from executive $\mathrm{SCI}$ to

$\mathrm{MCI} /$ dementia of $50 \%$ at 7 years.

Participants with SCCs showed atrophy of

orbital prefrontal regions and higher p-tau

and RM-SPARE-EA values (indicative of pathological changes).

\section{NEUROPSYCHOLOGY}

MMSE; categorical and phonemic fluency tests, Stroop test, path test and TMT A-B
Significantly lower pre-DCL-group scores in visual memory and executive functions, with poor performance in inhibition and goal-directed behavior.
Verfaillie et al. (2016) [40]
238 participants with SCI (109 W and $129 \mathrm{M})$

Mean age: 62 years

Country: Netherlands
NEUROPSYCHOLOGY

Neuropsychological assessment (MMSE) NEUROIMAGING

Measurement of cortical thickness by MRI
A total of $16 \%$ of participants showed progression to $\mathrm{MCI}$ and $\mathrm{AD}$ at the 2-3 year follow-up.

Reduced fronto-temporo-parietal cortical thickness associated with reduced memory performance.

Reduced temporal cortical thickness was associated with decreased executive performance. 
Table 1. Cont.

Authors

Fogarty et al. (2017) [41]

Viviano et al. (2018) [43]

\section{Sample}

Results

55 participants ( $35 \mathrm{~W}$ and $20 \mathrm{M}$ )

23 subjects with mild $\mathrm{AD}(9 \mathrm{~W}$ and $14 \mathrm{M}$ )

Mean age: 73.95 years

Mean years of education: 15.56

32 adult control subjects ( $26 \mathrm{~W}$ and $6 \mathrm{M}$ )

Mean age: 69.84 years

Mean years of education: 13.96

Country: England

1442 participants

1088 HC subjects

354 with SCCs

Country: South Korea

83 participants (51 $\mathrm{W}$ and $32 \mathrm{M}$ ):

35 adults with SCI (22 W and $13 \mathrm{M})$

Mean age: 68.5 years

48 adults without $\mathrm{SCI}$

$$
\text { (29 } \mathrm{W} \text { and } 19 \mathrm{M})
$$

Mean age: 67.08 year

Country: United States, Netherlands

68 normal subjects ( $46 \mathrm{~W}$ and $22 \mathrm{M}$ ):

$52 \mathrm{HC}(33 \mathrm{~W}$ and $19 \mathrm{M})$

Mean age: 63.87 years

Valech et al. (2018) [44]

Mean years of education: 11.96

16 pre-AD (13 W and $3 \mathrm{M}$ )

Mean age: 66.5 years

Mean years of education: 9.56

Country: Spain

195 participants with SCD (121 W and $74 \mathrm{M})$

Mean age: 65.71 years

Mean years of education: 14.94

Country: Spain
NEUROPSYCHOLOGY

Application of the BRIEF-A to participants and informants

(spouse/child)

NEUROPSYCHOLOGY

MMSE,

initiation/perseveration (IP), Subscale of the Korean version of Mattis Dementia

Rating Scale (K-DRS)

\section{NEUROPSYCHOLOGY}

MMSE and Weschler Memory Scale, Geriatric Depression

Scale, Beck Depression Inventory II

and Big Five Inventory

NEUROIMAGING

Assessment of functional connectivity of brain regions using MRI and

diffusion of regions

Neuropsychological follow-up for 1 year

$$
\text { NEUROPSYCHOLOGY }
$$

Subjective Cognitive Complaints Questionnaire (SCI-Q)

MMSE, Memory Alteration Test, Boston Naming Test,

comprehension of commands (BDAE), incomplete letters

and number location (VOSP), TMT-A, phonetic fluencie

(FAS), Free and Cued Selective Reminding Test

(FHCRT-IR), semantic fluency test (animals), Stroop tes Hospital Anxiety and Depression Scale

$$
\text { NEUROPSYCHOLOGY }
$$

TMT A-B, rule shift card subtest (BADS), automatic inhibition subtest (AI-SKT), digits (WAIS-III), letter, semantic and verbal fluency tests

$$
\text { NEUROIMAGING }
$$

Functional neuroimaging studies (positron emission tomography with 18F-Florbetaben and MRI) Analysis of gray matter volume
Participants with mild AD and their informants reported greater difficulties in most of the clinical scales assessed.

Participants with SCCs performed worse on all cognitive tests that evaluated memory and executive functions.

Patients and informants were more likely to report executive problems in working memory, planning/organising and monitoring.

Subjective cognitive impairment was associated with lower functional connectivity in retrosplenial-precuneus regions and memory-system regions (poorer performance in visual working memory).

Pre-AD subjects showed significantly higher scores with respect to language, attention and executive decline, confirmed by their informants.

Significantly decreased cognitive performance in pre-AD on tests of inhibition and semantic fluency.

Significant association between $\beta$-amyloid deposition and low executive performance in automatic inhibition (AI-SKT).

Low executive performance was associated with lower volume in bilateral hippocampal and left frontal regions. 
Table 1. Cont.

Authors

Kim et al. (2020) [46]

Esmaeili et al. (2021) [47]

\begin{tabular}{|c|c|c|c|}
\hline Authors & Sample & Methodology & Results \\
\hline Kim et al. (2020) [46] & $\begin{array}{l}1442 \text { participants ( } 886 \mathrm{~W} \text { and } 556 \mathrm{M}) \\
\text { (age: } \geq 65 \text { years): } \\
1088 \text { HC subjects }(642 \mathrm{~W} \text { and } 446 \mathrm{M}) \\
\text { Mean years of education: } 5.66 \\
354 \text { SCC subjects (244 W and } 110 \mathrm{M} \text { ) } \\
\text { Mean years of education: } 3.33 \\
\text { Country: Korea }\end{array}$ & $\begin{array}{c}\text { NEUROPSYCHOLOGY } \\
\text { Mini-Mental State Examination, Korean version } \\
\text { (MMSE-KC)—use of the recording and retrieval subscales } \\
\text { for memory assessment and the initiation/perseveration } \\
\text { subscales (Korean rating scale K-DRS) to assess } \\
\text { executive functions }\end{array}$ & $\begin{array}{l}\text { Significant relationship between depression } \\
\text { and SCCs. } \\
\text { Lower performance in global cognition, } \\
\text { memory and executive functions (verbal } \\
\text { fluency) in the study group. }\end{array}$ \\
\hline Esmaeili et al. (2021) [47] & $\begin{array}{c}62 \text { subjects: } \\
17 \text { SCC subjects } \\
30 \text { amnestic-MCI subjects } \\
15 \text { HC subjects } \\
\text { Country: Iran } \\
\end{array}$ & $\begin{array}{c}\text { NEUROPSYCHOLOGY } \\
\text { Attention Network Test (ANT) }\end{array}$ & $\begin{array}{l}\text { The older SCC subjects faced problems in } \\
\text { maintaining alertness to external stimuli } \\
\text { (attention-processing problems). }\end{array}$ \\
\hline Garrido et al. (2021) [48] & $\begin{array}{c}136 \text { subjects }(67 \mathrm{~W} \text { and } 59 \mathrm{M}) \text { : } \\
28 \text { young adults with SCCs }(17 \mathrm{~W} \text { and } 11 \mathrm{M}) \\
\text { Mean age: } 21 \text { years } \\
37 \text { young adults without SCCs }(16 \mathrm{~W} \text { and } 11 \mathrm{M}) \\
\text { Mean age: } 23 \text { years } \\
32 \text { older adults with SCCs }(18 \mathrm{~W} \text { and } 14 \mathrm{M}) \\
\text { Mean age: } 63 \text { years } \\
39 \text { older adults without SCCs }(16 \mathrm{~W} \text { and } 23 \mathrm{M}) \\
\text { Mean age: } 65 \text { years } \\
\text { Country: Spain }\end{array}$ & $\begin{array}{c}\text { NEUROPSYCHOLOGY } \\
\text { Iowa gambling task (IGT) } \\
\text { NEUROLOGY } \\
\text { Electroencephalogram (EEG) } \\
\text { Feedback-related negativity (FRN) }\end{array}$ & $\begin{array}{c}\text { The older adults with SCCs presented deficits } \\
\text { in the decision-making process. These data } \\
\text { were also observed in the neuronal } \\
\text { mechanisms studied. }\end{array}$ \\
\hline
\end{tabular}


The experimental designs included cross-sectional analyses to describe the executive performance of the studied population at a given time. In addition, a few longitudinal follow-up and prospective analyses were conducted. The descriptive studies corroborated the existence of a direct relationship between subjective cognitive complaints and the impairment of several executive processes, such as attention, working memory, initiative, cognitive flexibility, inhibition, planning, monitoring, verbal fluency, decision making and goal-directed behaviors [36,39,42,45-48]. These functions were directly associated with selfreported complaints from participants but also their informants $[34,41,43,44]$. On the other hand, the characterization of executive performance throughout the evolution of cognitive deterioration, based on cognitive complaints before or after clinical diagnosis, pointed to follow-up studies as essential not only to diagnose and monitor cognitive impairment but, more importantly, to determine a possible predictive relationship with subjective cognitive complaints. Thus, the longitudinal studies $[33,35,37,38,40,44]$ indicated that, in a variable percentage, people presenting subjective cognitive complaints showed a significant cognitive decline in executive processes during the progressive neuropsychological followups, evolving to a possible picture of mild cognitive impairment (MCI) or dementia. In addition, a 15-year prospective study on people with Alzheimer's disease showed that lower cognitive performance at the executive level started to become more pronounced 2-3 years prior to receiving a clinical diagnosis [35].

The application of standardized neuropsychological tests was the common tool in all the studies, with MMSE as a general screening tool to assess cognitive performance being used in seven of them. However, the review shows that the administration of classical screening tests or questionnaires to study cognitive impairment may not be sufficient for a detailed understanding of executive performance since they are not sensitive enough. Thus, inserting specific neuropsychological tools for executive functions is essential in any clinical analysis. Among them, the most used tests assessed verbal and semantic fluency, cognitive processes such as working memory (digits-WAIS), attentional control (digits, symbolsubstitution test and TMT A-B), initiation/perseveration (Korean rating scale K-DRS), BRIEF-A and inhibitory control (Stroop test). On the other hand, not all but some of the studies complemented the neuropsychological assessment with biological markers in the CSF or the use of neuroimaging $[37,38,40,43,45,48]$. Despite the high cost of neuroimaging studies and their limitations in terms of specificity and power resolution in the initial clinical analysis, which limits their applicability in the population with subjective cognitive complaints, the studies related executive performance to the presence of biomarkers in the CSF and to reductions detected by regional volumetric analyses. Interestingly, a direct relationship between CSF biomarkers present in the preclinical stages of dementia and the impairment of executive processes was found. Thus, higher p-tau values and $\beta$-amyloid deposition were associated with subjective cognitive complaints and lower performance in executive functions such as inhibition [37,38,45]. Similarly, neuroimaging studies revealed a direct relationship between subjective cognitive complaints and atrophy of orbital prefrontal regions, reduced functional connectivity in retrosplenial-precuneus regions, reduced temporal cortical thickness (bilateral hippocampi) and left frontal regions, associated with decreased executive performance $[38,40,43,45]$.

\section{Discussion}

The first observation of this systematic review is that, despite the scarcity of literature focusing on the early study of cognitive decline in executive processes, there is a recent growing interest in the prodromal stages of this cognitive domain and the potential predictive value of subjective complaints in this respect. The data corroborate the relationship among subjective cognitive impairment and executive functioning, the relevance of not underestimating the patients' and/or informants' complaint reports. However, the data can be considered inconclusive, a fact that may be due to the rather small number of SCI patients used in most of the studies, as well as the heterogeneity of the neuropsychological tools used and multiple variables involved. Consistency regarding the screening tools is 
needed. Complementing neuropsychological screening with biomarkers and neuroimaging was presented as critical to confirm the early changes in neurological substrates potentially underlying the subjective complaints. Still, despite the complexity of the studies with biomarkers, some studies used almost only MMSE, a test with global acceptance but without the necessary specificity and sensitivity to assess SCI or even MCI patients.

The need for further research and guidelines is enhanced in the current aging population [1] and the global health situation, where the number of middle-aged people with cognitive complaints has dramatically increased [24,25]. The most recent work, a systematic review on the relationship between subjective cognitive complaints and informants' reports, by Wasef et al. [49] in the context of anesthesiology, provides a general description of the number of cognitive domains affected, with executive functions figuring among them.

Studies assessing executive characteristics in patients with a defined diagnosis, analyzing their impact on a possible prognosis, were more common. For instance, people with amnestic mild cognitive impairment (aMCI) exhibiting frontal executive dysfunction at baseline had overall cortical thinning, including frontal areas, and a higher risk of dementia conversion than those exhibiting visuospatial or language dysfunction [50]. In that clinical scenario, confirming this poor prognosis was essential to determine the higher priority of this subgroup for intervention therapy among aMCI patients. Similarly, proper consideration of the reliability and possible predictive value of subjective cognitive complaints and a better understanding of the early stages of cognitive decline in executive functions would help to define timely interventions in a population that may be at risk. In this sense, comprehensive educational group interventions in community-dwelling older women reporting normal age-related cognitive complaints in the absence of actual cognitive decline were shown to be effective [51]. Complainers receiving psycho-education about cognitive aging and contextual factors, including health, lifestyle, beliefs and negative age stereotypes, reported significatively fewer negative emotional reactions towards cognitive functioning, considered by the authors as a prerequisite for improved subjective cognitive functioning and wellbeing.

Studies analyzing the need to include tools (self-reports) that assess more executive processes such as working memory rather than declarative memory processes also advocated for the relevance of multiple-cognitive-domain screening compared to classical unidimensional cognitive assessments [52]. Thus, one of the limitations in the analyzed studies was the generalization in neurocognitive assessments. Despite the use of more-orless-specific tests for executive functioning, the study of memory as a unitary process and predictor of dementia continued to be prioritized. However, authors such as Giovanello and Verfaille [53] considered the need to study memory as a multimodal process related to other cognitive functions, making it possible to analyze the relationship of this process with cognitive impairment in-depth. In this sense, the study of specific memory modalities would be associated with executive processes and the activation of frontal regions, which could be associated with preclinical stages of dementia. Types of memory such as prospective memory and metamemory associated with self-awareness of illness are processes that have been investigated in recent years concerning cognitive complaints and executive functioning, as they share a common anato-functional niches, such as the prefrontal cortex [54-57].

In the same vein, self-reports and reports from external informants can work as sentinels providing valuable information about executive functioning at preclinical stages. Fogarty (2017) [41] stated that people with mild AD had more significant concerns regarding their executive functions associated with their daily lives, an opinion which was corroborated, to a lesser extent, by their informants. However, other studies indicated that only self-reported cognitive complaints predicted future cognitive changes and were associated with executive functioning, unlike informants' reports being associated with other cognitive processes [58,59].

Highly heterogeneous variables influence subjective cognitive complaints, contributing to underestimating the reliability of this psychological construct. Emotional factors and 
affective disorders, including depression and anxiety, negatively influence memory but also executive performance. To monitor their contribution, some of the revised studies included neuropsychiatric symptoms in clinical assessments [60,61]. In addition, personality factors can directly influence the self-perception of everyday failures, which could be associated with executive problems [62]. Still, none of the revised works on subjective cognitive complaints and executive functions considered nor assessed the contribution of age stereotypes. In fact, only a few research reports in the literature have specifically studied subjective cognitive complaints and age stereotypes [12,63]. Lubitz et al. [63] recently developed and assessed the psychometric properties of a new questionnaire on subjective cognitive complaints in multiple cognitive domains, its association with psychological variables and the distinction of complainer types. Their study confirmed the strong influence of depressiveness on the overall level of subjective cognitive complaints. Most importantly, it detected that people with complaints about executive functions exhibited the highest levels of affective disorders, were younger and had less social integration.

Depressive symptoms and memory impairments are associated with heightened stress hormone levels during aging; conversely, long-term exposure to high endogenous levels of glucocorticoids is associated with both memory impairment and smaller hippocampal volume. In this context, Sindi et al. [12] studied the role of internalized negative aging perceptions and found them to be associated with increased depressive symptoms and subjective-but not objective-memory complaints. Interestingly, negative age stereotypes did not predict increased cortisol levels, suggesting that the mechanism underlying the association between stereotypes and cognitive impairments may be independent of agerelated dysregulations of cortisol secretion [12]. However, although depression and stress contribute to cognitive performance, almost none of the studies used as an obligatory criterion the absence of psychiatric comorbidity.

The studies analyzed in the present review did not provide conclusive data about the relationship among sociodemographic variables, such as gender and level of education, that may influence the individual's subjective perceptions and executive impairment. Nevertheless, gender medicine considers essential to analyze the effects of sex and gender [64,65] and a recent research study found significant differences in executive performance between men and women with subjective cognitive complaints, with men performing worse than women [66]. On the other hand, in the study, there was minimal specificity of participants' level of education and its relationship as a possible predictor of dementia. In this sense, we recently confirmed the relevance of considering the interactions between sex/gender and education factors, since a lower level of education in women can be a critical risk factor for dementia in vulnerable subjects [67].

\section{Conclusions}

In conclusion, the study of subjective cognitive complaints and their relation to executive functioning draws attention to several dimensions of clinical interest; therefore, it can be foreseen to be a promising emerging field. However, the specific search for information in this regard will find limitations as long as the term "subjective cognitive complaints" remains ambiguous and does not have a precise definition. Psychiatric comorbidity should be considered as a confounding factor, thus an exclusion criterion. Studies including a rather small number of SCI patients, no consistency regarding tools and the general use of MMSE are other limitations of the current literature.

The studies corroborated the relationship between subjective cognitive complaints and some executive processes, which is noteworthy since many people with subjective executive complaints progress to dementia. The relational studies confirmed that impaired executive performance was associated with CSF biomarkers and reduced cortical volume in specific brain regions. However, it is necessary to focus on unifying the screening tools based on processes rather than isolated functions when studying the significant heterogeneity involved in this preclinical construct. Applying an adequate neuropsychological assessment in parallel to the clinical study and a detailed analysis of sociodemographic variables 
would allow a better definition of the neurocognitive profile of adults who report executive complaints in their daily lives to be obtained. Otherwise, there is a risk of underestimating the reliability and predictive value of self-reporting, which may hamper the chances of providing an adequate diagnosis and early and timely intervention.

Author Contributions: Conceptualization, F.W.-C. and L.G.-L.; methodology, F.W.-C.; writingoriginal draft preparation, F.W.-C.; writing-review and editing, F.W.-C. and L.G.-L.; supervision, L.G.-L.; funding acquisition, L.G.-L. All authors have read and agreed to the published version of the manuscript.

Funding: Memorial Mercedes Llort Sender 2021/80/09241941.5.

Institutional Review Board Statement: Not applicable.

Informed Consent Statement: Not applicable.

Data Availability Statement: Not applicable.

Conflicts of Interest: The authors declare no conflict of interest.

\section{References}

1. Arai, H.; Ouchi, Y.; Yokode, M.; Ito, H.; Uematsu, H.; Eto, F.; Oshima, S.; Ota, K.; Saito, Y.; Sasaki, H.; et al. Members of Subcommittee for Aging. Toward the realization of a better aged society: Messages from gerontology and geriatrics. Geriatr. Gerontol. Int. 2012, 12, 16-22. [CrossRef]

2. Marquet, M.; Missotten, P.; Adam, S. Ageism and overestimation of cognitive difficulties in older people: A review. Geriatr. Psychol. Neuropsychiatr. Vieil. 2016, 14, 177-186. [CrossRef] [PubMed]

3. Mazerolle, M.; Régner, I.; Morisset, P.; Rigalleau, F.; Huguet, P. Stereotype threat strengthens automatic recall and undermines controlled processes in older adults. Psychol. Sci. 2012, 23, 723-727. [CrossRef] [PubMed]

4. Barber, S.J.; Lee, S.R. Stereotype Threat Lowers Older Adults' Self-Reported Hearing Abilities. Gerontology 2015, 62, 81-85. [CrossRef] [PubMed]

5. Masse, M.; Meire, P. Is ageism a relevant concept for health care practice in the elderly? Geriatr. Psychol. Neuropsychiatr. Vieil. 2012, 10, 333-341. [CrossRef]

6. Barber, S.J. An Examination of Age-Based Stereotype Threat about Cognitive Decline. Perspect. Psychol. Sci. 2017, 12, 62-90. [CrossRef]

7. Marquet, M.; Missotten, P.; Dardenne, B.; Adam, S. Interactions between stereotype threat, subjective aging, and memory in older adults. Neuropsychol. Dev. Cogn. B Aging Neuropsychol. Cogn. 2019, 26, 121-143. [CrossRef]

8. Smith, A.M.; Gallo, D.A.; Barber, S.J.; Maddox, K.B.; Thomas, A.K. Stereotypes, Warnings, and Identity-Related Variables Influence Older Adults' Susceptibility to Associative False Memory Errors. Gerontologist 2017, 57 (Suppl. S2), S206-S215. [CrossRef]

9. Armstrong, B.; Gallant, S.N.; Li, L.; Patel, K.; Wong, B.I. Stereotype Threat Effects on Older Adults' Episodic and Working Memory: A Meta-Analysis. Gerontologist 2017, 57 (Suppl. S2), S193-S205. [CrossRef]

10. Thomas, A.K.; Smith, A.M.; Mazerolle, M. The Unexpected Relationship between Retrieval Demands and Memory Performance When Older Adults Are Faced with Age-Related Stereotypes. J. Gerontol. B Psychol. Sci. Soc. Sci. 2020, 75, 241-250. [CrossRef]

11. Wurm, S.; Diehl, M.; Kornadt, A.E.; Westerhof, G.J.; Wahl, H.W. How do views on aging affect health outcomes in adulthood and late life? Explanations for an established connection. Dev. Rev. 2017, 46, 27-43. [CrossRef]

12. Sindi, S.; Juster, R.P.; Wan, N.; Nair, N.P.; Ying Kin, N.; Lupien, S.J. Depressive symptoms, cortisol, and cognition during human aging: The role of negative aging perceptions. Stress 2012, 15, 130-137. [CrossRef]

13. Weiss, D. On the Inevitability of Aging: Essentialist Beliefs Moderate the Impact of Negative Age Stereotypes on Older Adults' Memory Performance and Physiological Reactivity. J. Gerontol. B Psychol. Sci. Soc. Sci. 2018, 73, 925-933. [CrossRef]

14. Mazerolle, M.; Régner, I.; Barber, S.J.; Paccalin, M.; Miazola, A.C.; Huguet, P.; Rigalleau, F. Negative Aging Stereotypes Impair Performance on Brief Cognitive Tests Used to Screen for Predementia. J. Gerontol. B Psychol. Sci. Soc. Sci. 2017, 72, 932-936. [CrossRef]

15. Jessen, F.; Amariglio, R.E.; van Boxtel, M.; Breteler, M.; Ceccaldi, M.; Chételat, G.; Wagner, M. A conceptual frame work for research on subjective cognitive decline in preclinical Alzheimer's disease. Alzheimer's Dement. 2014, 10, 844-852. [CrossRef]

16. Gallassi, R.; Oppi, F.; Poda, R.; Scortichini, S.; Stanzani Maserati, M.; Marano, G.; Sambati, L. Are subjective cognitive complaints a risk factor for dementia? Neurol. Sci. 2010, 31, 327-336. [CrossRef]

17. Perrote, M.; Brochero, N.; Concari, I.; García, I.; Assante, M.; Lucero, C. Association between subjective memory loss, mild cognitive impairment and dementia. Neurol. Argent. 2017, 9, 156-162. [CrossRef]

18. Brailean, A.; Steptoe, A.; Batty, G.D.; Zaninotto, P.; Llewellyn, D.J. Are subjective memory complaints indicative of objective cognitive decline or depressive symptoms? Findings from the English Longitudinal Study of Ageing. J. Psychiatr. Res. 2019, 110, 143-151. [CrossRef] 
19. Mias, C.; Causse, B. Subjective complaints of memory, objective performance and related neuropsychological functions. A systematic review. Perspect. Metodol. 2021, 21, 376-393.

20. Ruiz-Sánchez de León, J.M.; Llanero-Luque, M.; Lozoya-Delgado, P.; Fernández-Blázquez, M.A.; Pedrero-Pérez, E.J. Neuropsychological study of young adults with subjective memory complaints: Involvement of executive functions and other associated symptoms. Rev. Neurol. 2010, 51, 650-660.

21. Carrillo-Mora, P.; García-Juárez, B.; Lugo-Rodríguez, Y.; Moreno-Méndez, E.; Cruz-Alcalá, L. Subjective memory complaints in geriatric population and their associated factors: A pilot study in Mexican population. Rev. Mex. Neurocienc. 2017, $18,20-31$. Available online: https:/ /www.medigraphic.com/pdfs/revmexneu/rmn-2017/rmn176b.pdf (accessed on 7 January 2022).

22. Montejo-Carrasco, P.; Claver-Martín, M.; Montenegro-Peña, M.; Álvarez-Crespo, B.; Montejo-Rubio, B. Association of quality of life with episodic memory performance. Study in older people without cognitive impairment. Psicogeriatría 2016, 6, 69-80.

23. Pellicer-Porcar, O.; Mirete-Fructuoso, M.; Molina-Rodríguez, S.; Soto-Amaya, J. Subjective memory complaints in young adults: Influence of emotional state. Rev. Neurol. 2014, 59, 543-550.

24. Miskowiak, K.W.; Johnsen, S.; Sattler, S.M.; Nielsen, S.; Kunalan, K.; Rungby, J.; Lapperre, T.; Porsberg, C.M. Cognitive impairments four months after COVID-19 hospital discharge: Pattern, severity and association with illness variables. Eur. Neuropsychopharmacol. 2021, 46, 39-48. [CrossRef] [PubMed]

25. Ferrer-Torres, A.; Giménez-Llort, L. Confinement and the Hatred of Sound in Times of COVID-19: A Molotov Cocktail for People With Misophonia. Front. Psychiatry 2021, 12, 627044. [CrossRef] [PubMed]

26. Slavin, M.; Sachdev, P.; Kochan, N.; Woolf, C.; Crawford, J.; Giskes, K.; Reppermund, S.; Trollor, J.; Draper, B.; Delbaere, K.; et al Predicting Cognitive, Functional, and Diagnostic Change over 4 Years Using Baseline Subjective Cognitive Complaints in the Sydney Memory and Ageing Study. Am. J. Geriatr. Psychiatry 2015, 23, 906-914. [CrossRef] [PubMed]

27. Díaz-Orueta, U.; Blanco-Campal, A.; Burke, T. Process-based neuropsychological evaluation: Review of the evidence and proposal for the improvement of dementia screening tools. Rev. Neurol. 2017, 64, 514-524.

28. Barandiaran, M. Neuropsychology and early diagnosis. Rev. Esp. Geriatr. Gerontol. 2019, 46, 42-46. [CrossRef]

29. Garcia-Ptacek, S.; Eriksdotter, M.; Jelic, V.; Porta-Etessam, V.; Kåreholt, I.; y Manzano, S. Subjective cognitive impairment: Towards early identification of Alzheimer disease. Neurology 2016, 31, 562-571. [CrossRef]

30. Rolstad, S.; Berg, A.I.; Bjerke, M.; Blennow, K.; Johansson, B.; Zetterberg, H.; Wallin, H. Amyloid-beta42 is associated with cognitive impairment in healthy elderly and subjective cognitive impairment. J. Alzheimer's Dis. 2011, 26, 135-142. [CrossRef]

31. Saykin, A.J.; Wishart, H.A.; Rabin, L.A.; Santulli, R.B.; Flashman, L.A.; West, J.D.; McHugh, T.L.; Mamourian, A. Older adults with cognitive complaints show brain atrophy similar to that of amnestic mci. Neurology 2006, 67, 834-842. [CrossRef]

32. Urrutia, G.; Bonfill, X. La declaración PRISMA: Un paso adelante en la mejora de las publicaciones de la Revista Española de Salud Pública. Rev. Esp. Salud. Publica 2013, 87, 99-102. [CrossRef]

33. Rapp, M.A.; Reischies, F.M. Attention and executive control predict Alzheimer disease in late life: Results from the Berlin Aging Study (BASE). Am. J. Geriatr. Psychiatry 2005, 13, 134-141. [CrossRef]

34. Rabin, L.; Roth, R.; Isquith, P.; Wishart, H.; Nutter-Upham, K.; Pare, N.; Flashman, L.; Saykin, A. Self- and informant reports of executive function on the BRIEF-A in MCI and older adults with cognitive complaints. Arch. Clin. Neuropsychol. 2006, 21, 721-732. [CrossRef]

35. Grober, E.; Hall, C.B.; Lipton, R.B.; Zonderman, A.B.; Resnick, S.M.; Kawas, C. Memory impairment, executive dysfunction, and intellectual decline in preclinical Alzheimer's disease. J. Int. Neuropsychol. Soc. 2008, 14, 266-278. [CrossRef]

36. Saunders, N.L.; Summers, M.J. Attention and working memory deficits in mild cognitive impairment. J. Clin. Exp. Neuropsychol. 2010, 32, 350-357. [CrossRef]

37. Van Harten, A.C.; Smits, L.L.; Teunissen, C.E.; Visser, P.J.; Koene, T.; Blankenstein, M.A.; Scheltens, P.; van der Flier, W.M. Preclinical AD predicts decline in memory and executive functions in subjective complaints. Neurology 2013, 81, 1409-1416. [CrossRef]

38. Toledo, J.B.; Bjerke, M.; Chen, K.; Rozycki, M.; Jack, C.R.; Weiner, M.W.; Arnold, S.E.; Reiman, E.M.; Davatzikos, C.; Shaw, L.M.; et al. Memory, executive, and multidomain subtle cognitive impairment. Neurology 2015, 85, 144-153. [CrossRef]

39. Seo, E.H.; Kim, H.; Lee, K.H.; Choo, I.H. Altered Executive Function in Pre-Mild Cognitive Impairment. J. Alzheimer's Dis. 2016, 54, 933-940. [CrossRef]

40. Verfaillie, S.C.; Slot, R.E.; Tijms, B.; Bouwman, F.H.; Benedictus, M.; Overbeek, J.; Koene, T.; Vrenken, H.; Scheltens, P.; Barkhof, F.; et al. Thinner cortical thickness in patients with subjective cognitive decline is related to poor memory performance and faster decline of executive function. Alzheimer's Dement. J. Alzheimer's Assoc. 2016, 12, 113-114. [CrossRef]

41. Fogarty, J.; Almklov, E.; Borrie, M.; Wells, J.; Roth, R.M. Subjective rating of executive functions in mild Alzheimer's disease. Aging Ment. Health 2017, 21, 1184-1191. [CrossRef]

42. Bae, J.; Kim, W.; Kim, B.; Chang, S.; Lee, D.; Cho, M. Associations between subjective memory complaints and executive functions in a community sample of elderly without cognitive dysfunction. Alzheimer's Dement. 2017, 13, 1183. [CrossRef]

43. Viviano, R.P.; Hayes, J.M.; Pruitt, P.J.; Fernandez, Z.J.; van Rooden, S.; van der Grond, J.; Rombouts, S.; Damoiseaux, J.S. Aberrant memory system connectivity and working memory performance in subjective cognitive decline. Neuroimage 2019, 15, 556-564. [CrossRef] 
44. Valech, N.; Tort-Merino, A.; Coll-Padrós, N.; Olives, J.; León, M.; Rami, L.; Molinuevo, J.L. Executive and Language Subjective Cognitive Decline Complaints Discriminate Preclinical Alzheimer's Disease from Normal Aging. J. Alzheimer's Dis. 2018, 61, 689-703. [CrossRef]

45. Pérez-Cordón, A.; Monté-Rubio, G.; Sanabria, A.; Rodriguez-Gomez, O.; Valero, S.; Abdelnour, C.; Marquié, M.; Espinosa, A.; Ortega, G.; Hernandez, I.; et al. Subtle executive deficits are associated with higher brain amyloid burden and lower cortical volume in subjective cognitive decline: The FACEHBI cohort. Sci. Rep. 2020, 10, 17721. [CrossRef]

46. Kim, W.H.; Kim, B.S.; Chang, S.M.; Lee, D.W.; Bae, J.N. Relationship between subjective memory complaint and executive function in a community sample of South Korean elderly. Psychogeriatrics 2020, 20, 850-857. [CrossRef]

47. Esmaeili, M.; Nejati, V.; Shati, M.; Vatan, R.F.; Chehrehnegar, N.; Foroughan, M. Attentional network changes in subjective cognitive decline. Aging Clin. Exp. Res. 2021, 1-9. [CrossRef]

48. Garrido-Chaves, R.; Perez, V.; Perez-Alarcón, M.; Crespo-Sanmiguel, I.; Paiva, T.O.; Hidalgo, V.; Pulopulos, M.M.; Salvador, A Subjective MemoryComplaints and Decision Making in Young and Older Adults: An Event-Related Potential Study. Front. Aging Neurosci. 2021, 13, 695275. [CrossRef]

49. Wasef, S.; Laksono, I.; Kapoor, P.; Tang-Wei, D.; Gold, D.; Saripella, A.; Riazi, S.; Islam, S.; Englesakis, M.; Wong, J.; et al. Screening for subjective cognitive decline in the elderly via subjective cognitive complaints and informant-reported questionnaires: A systematic review. BMC Anesthesiol. 2021, 21, 277. [CrossRef] [PubMed]

50. Jung, Y.H.; Park, S.; Jang, H.; Cho, S.H.; Kim, S.J.; Kim, J.P.; Kim, S.T.; Na, D.L.; Seo, S.W.; Kim, H.J. Frontal-executive dysfunction affects dementia conversion in patients with amnestic mild cognitive impairment. Sci. Rep. 2020, 10, 772. [CrossRef] [PubMed]

51. Hoogenhout, E.M.; de Groot, R.H.; van der Elst, W.; Jolles, J. Effects of a comprehensive educational group intervention in older women with cognitive complaints: A randomized controlled trial. Aging Ment. Health 2012, 16, 135-144. [CrossRef]

52. Almkvist, O.; Bosnes, O.; Bosnes, I.; Stordal, E. Subjective working and declarative memory in dementia and normal aging. Acta Neurol. Scand. 2019, 140, 140-146. [CrossRef]

53. Giovanello, K.S.; Verfaille, M. Memory systems of the brain: A cognitive neuropsychological analysis. Semin. Speech Lang. 2001, 22, 107-116. [CrossRef] [PubMed]

54. Grady, C. The cognitive neuroscience of aging. Nat. Rev. Neurosci. 2012, 13, 491-505. [CrossRef]

55. Rabin, L.A.; Chi, S.Y.; Wang, C.; Fogel, J.; Kann, S.J.; Aronov, A. Prospective memory on a novel clinical task in older adults with mild cognitive impairment and subjective cognitive decline. Neuropsychol. Rehabil. Int. J. 2014, 24, 868-893. [CrossRef]

56. Lee, S.D.; Ong, B.; Pike, K.E.; Kinsella, G.J. Prospective memory and subjective memory decline: A neuropsychological indicator of memory difficulties in community-dwelling older people. J. Clin. Exp. Neuropsychol. 2018, 40, 183-197. [CrossRef]

57. Amanzio, M.; Bartoli, B.; Cipriani, G.E.; Palermo, S. Executive Dysfunction and Reduced Self-Awareness in Patients with Neurological Disorders. A Mini-Review. Front. Psychol. 2020, 11, 1697. [CrossRef]

58. Vaskivuo, L.; Hokkanen, L.; Hänninen, T.; Antikainen, R.; Bäckman, L.; Laatikainen, T.; Paajanen, T.; Stigsdotter-Neely, A.; Strandberg, T.; Tuomilehto, J.; et al. Self and Informant Memory Reports in FINGER: Associations with Two-Year Cognitive Change. J. Alzheimer's Dis. 2019, 71, 785-795. [CrossRef]

59. De Almeida, M.L.; Dalpubel, D.; Ribeiro, E.B.; de Oliveira, E.S.B.; Ansai, J.H.; Vale, F.A.C. Subjective cognitive impairment, cognitive disorders and self-perceived health: The importance of the informant. Dement. Neuropsychol. 2019, 13, 335-342. [CrossRef]

60. Baquero, M.; Martin, N. Depressive symptoms in neurodegenerative diseases. World J. Clin. Cases 2015, 3, 682-693. [CrossRef]

61. Sánchez-Negrete, M.G.; Igol, P.; Mandich, V.C.; Lascar, M. Ansiedad, depresión y quejas cognitivas. In VIII Congreso Internacional de Investigación y Práctica Profesional en Psicología XXIII Jornadas de Investigación XII Encuentro de Investigadores en Psicología del MERCOSUR; Facultad de Psicología-Universidad de Buenos Aires: Buenos Aires, Argentina, 2016.

62. Pedrero-Pérez, E.J.; Ruiz-Sánchez de León, J.M. Subjective complaints of memory, personality and prefrontal symptoms in young adults. Rev. Neurol. 2013, 57, 289-296. [PubMed]

63. Lubitz, A.F.; Eid, M.; Niedeggen, M. Complainer Profile Identification (CPI): Properties of a new questionnaire on subjective cognitive complaints. Neuropsychol. Dev. Cogn. B Aging Neuropsychol. Cogn. 2018, 25, 99-121. [CrossRef] [PubMed]

64. Baggio, G.; Corsini, A.; Floreani, A.; Giannini, S.; Zagonel, V. Gender medicine: A task for the third millennium. Clin. Chem. Lab. Med. 2013, 51, 713-727. [CrossRef]

65. Giménez-Llort, L. The Moon Effect: Individual and Social Impact of Aging in Men and Women on the Third Millennium. In Proceedings of the 19th IPA International Congress, Santiago de Compostela, Spain, 31 August-3 September 2019. [CrossRef]

66. Wang, L.; Tian, T. Gender Differences in Elderly with Subjective Cognitive Decline. Front. Aging Neurosci. 2018, 10, 166. [CrossRef]

67. Oghagbon, E.K.; Giménez-Llort, L. Short height and poor education increase the risk of dementia in Nigerian type 2 diabetic women. Alzheimer's Dement. 2019, 11, 493-499. [CrossRef] 